\section{EFFICACY OF HIGH AND LOW DOSE ORAL VITAMIN D REPLACEMENT THERAPY IN INFLAMMATORY BOWEL DISEASE (IBD): SINGLE CENTRE COHORT}

H J Hiew, M Naghibi, J Wu, J Saunders, F Cummings, T R Smith Department of Gastroenterology, University Hospital Southampton, Southampton, Hampshire, UK

10.1136/gutjnl-2013-305143.4

Introduction IBD patients are at risk of micronutrient deficiency including vitamin $\mathrm{D}$. There is evidence that vitamin $\mathrm{D}$ deficiency is associated with poor disease activity.

Aims/Background To determine the vitamin D status and evaluate the effectiveness of oral vitamin $\mathrm{D}$ treatment in a sub-set of IBD patients at a University Hospital.
Method All IBD patients with serum vitamin D levels measured in 2011 were identified. Vitamin D deficiency was determined as plasma 25-hydroxyvitamin D levels $<52 \mathrm{nmol} / \mathrm{L}$. Oral vitamin D treatment was classified as 'low dose' when patients prescribed daily 800 units of vitamin D2/D3 and 'high dose' when given either 100 '000 units once or 50'000 units weekly for 6 weeks. Treatment response was assessed within 6 months of treatment.

Results 205 IBD patients had their plasma vitamin D measured. 95 (46\%) were found to be vitamin D deficient with no significant difference in the prevalence between Crohn's disease (CD) and ulcerative colitis $(\mathrm{UC})$ patients $(\mathrm{p}=0.449) .32$ treatment episodes had follow up measurement. Those who received 'high dose' regimen demonstrated a $150 \%$ increase in plasma vitamin D compared to a $34 \%$ increase in those put on 'low dose' regimen $(p=0.001)$. There was no significant difference in treatment response between CD and UC patients $(p=0.874)$ (table 1).

Conclusion Oral vitamin D replacement is an effective treatment for vitamin D deficiency in IBD patients and appears to be dose responsive, in both UC and CD patients. The optimal dose of oral vitamin D supplementation is yet to be determined, but higher doses are significantly more effective.

Table 1 Plasma vitamin D response to differing doses of oral treatment in CD and UC

\begin{tabular}{|c|c|c|c|c|c|c|c|c|}
\hline & Subjects & $\begin{array}{l}\text { Vitamin D } \\
\text { deficient (\%) }\end{array}$ & $\begin{array}{l}\text { Treated orally+follow-up } \\
\text { Vitamin D available }\end{array}$ & $\begin{array}{l}\% \text { increase in } \\
\text { plasma vitamin D }\end{array}$ & $\begin{array}{l}\text { High } \\
\text { dose } R x\end{array}$ & $\begin{array}{l}\% \text { increase in } \\
\text { plasma vitamin D }\end{array}$ & $\begin{array}{l}\text { Low } \\
\text { dose } \mathrm{Rx}\end{array}$ & $\begin{array}{l}\% \text { increase in } \\
\text { plasma vitamin D }\end{array}$ \\
\hline All subjects & 205 & $95(46)$ & 32 & 115 & 24 & 150 & 8 & 34 \\
\hline UC & 70 & $35(50)$ & 11 & 100 & 8 & 167 & 3 & 47 \\
\hline All CD & 135 & $60(44)$ & 21 & 116 & 16 & 150 & 5 & 29 \\
\hline Ileocolonic CD & 45 & 20 (44) & 9 & 132 & 7 & 156 & 2 & 13 \\
\hline Colonic CD & 36 & $15(42)$ & 5 & 64 & 3 & 114 & 2 & 46 \\
\hline $\begin{array}{l}\text { Small } \\
\text { bowel -CD }\end{array}$ & 54 & $25(46)$ & 7 & 145 & 6 & 173 & 1 & 14 \\
\hline
\end{tabular}

